\title{
Ön çapraz bağ yaralanmasının mekanizması ve önlenmesi
}

\section{Mechanism and prevention of anterior cruciate ligament rupture}

\author{
Fatih Karaaslan ${ }^{1}$, Turan Cihan Dülgeroğlu² \\ ${ }^{1}$ Dünyam Hastanesi, Ortopedi ve Travmatoloji Kliniği, Kayseri \\ ${ }^{2}$ Kütahya Sağlık Bilimleri Üniversitesi, Ortopedi ve Travmatoloji Anabilim Dalı, Kütahya
}

Ön çapraz bağ (ÖÇB) rüptürü özellikle yüksek enerjili sportif aktivitelerde temas içermeyen pivot shift mekanizması ve valgus zorlanma içeren tibial rotasyonel hareket sonucunda oluşur. ÖÇB yaralanmalarına zemin hazırlayan nedenler arasında anatomik yapısal sorunlar, cinsiyet, kas ve nörolojik koordinasyon problemleri, iklim şartları, saha ve zemin problemleri benzeri birçok iç ve dış faktörler sayılabilir. Bu faktörlerin büyük bir kısmı maalesef değiştirilememektedir.

Anahtar sözcükler: ön çapraz bağ; yaralanma mekanizması; risk faktörleri; temaslı travma; temassız travma
Anterior cruciate ligament (ACL) rupture is seen as a result of tibial rotational activity involving non-contact pivot shift mechanism and valgus movement, especially in high energy sports activities. ACL injuries occur due to many internal and external factors such as anatomical structural problems, sportive activity type, gender, muscle and neurological coordination problems, climatic conditions, field and ground problems, while some of these factors can be changed, most of them cannot be changed.

Key words: anterior cruciate ligament; injury mechanism; risk factors; direct trauma; indirect trauma
D ünya çapında 212 milyon birey yarışma için ya da günlük bireysel spor aktivitesi amacı ile spor yapmaktadır. Spor aktivitelerinde ön çapraz bağ (ÖÇB) yaralanması diz ekleminin tipik yaralanmalarındandır. ${ }^{[1]}$ Son 20 yılda tamir ve rehabilitasyon metotlarının gelişmesi ile birlikte ÖÇB'si yaralanan hastanın cerrahi sonrasında eski spor aktivite seviyesine ulaşmasını sağlamıştır. Ancak bu becerilere rağmen hastanın eski seviyesine ulaşması her zaman mümkün olamamaktadır ve istenen seviyeye ulaşmak oldukça uzun süre almaktadır. İyileşme süreci hastaya mental, fizyolojik ve ekonomik yükler getirmektedir. Dolayısıyla bu faktörler göz önüne alındığında; ÖÇB yaralanmasından korunmak oldukça fazla öneme sahiptir. ${ }^{[1,2]}$

Ön çapraz bağ (ÖÇB) yaralanması temassız ve temaslı yaralanmalar sonucunda gözlenir. ${ }^{[1]}$ ÖÇB rüptürlerinin yaklaşık dörtte üçü temassız yaralanmalar sonucu meydana gelir. Kadın sporcular benzer sporu yapan erkek sporculara kıyasla 2-8 kat daha fazla risk altındadır. ${ }^{[2]}$ Öncelikle yaralanma mekanizmasının anlaşılması, yaralanmaya maruziyeti en aza indirecektir. ${ }^{[3]}$
Yaralanmaya zemin hazırladığı öne sürülen, interkondiler aralıkta sıkışma, eklemin lateral yüzünde aksiyel kompresif yüklerin fazlalığı, kuadriseps tendon kontraksiyonu ve kuadriseps-hamstring güç dengesinin bozulması ile ilgili teoriler öne sürülmüştür. Kadın sporcularda daha yüksek oranda görülmesinin nedeni olarak eklem laksitesi, valgus ve abduksiyon momentleri ve genu rekurvatum gibi anatomik zeminli teoriler öne sürülmüştür. ${ }^{[4-7]}$ ÖÇB yaralanmasına neden olacak nedenlerin ve risk faktörlerinin ortaya konulması ve önleyici tedbirlerin alınması oldukça önemlidir. Risk faktörlerini dış (çevresel, ekstrinsik) kaynaklı ve iç (bireysel, intrinsik) kaynaklı olarak ikiye ayırabiliriz. İç kaynaklı faktörler bireye özgüdür, değiştirilebilen ve değiştirilemeyen olarak ikiye ayırarak incelemekte yarar görüyoruz. Kas gücü ve esneme kabiliyeti değiştirilebilen bireysel faktörlere örnek olarak verilecek olursa, değiştirilemeyen risk faktörleri arasında ilk olarak bireyin anatomik özellikleri gelmektedir. ${ }^{[8]}$ Benzer olarak dış nedenli risk faktörleri; dış etkenlerdir ve bireyler tarafından değiştirilememektedir (oyun zemini, iklim koşulları). Değiştirilebilen risk faktörleri üzerinde

- Illetişim adresi: Doç. Dr. Fatih Karaaslan, Dünyam Hastanesi, Ortopedi ve Travmatoloji, Kayseri

Tel: 0505 - 4679140 e-posta: fkaraaslan@gmail.com

- Geliș tarihi: 9 Nisan $2020 \quad$ Kabul tarihi: 24 Nisan 2020 
odaklanılarak ve koruyucu tedbirler üzerinde durularak ÖÇB yaralanması riski daha düşük oranlara indirgenebilir. ${ }^{\left[{ }^{[9]}\right.}$ Dış kaynaklı risk faktörleri üzerinde çalışarak ve özellikle spor saha zeminlerinin şartları iyileştirerek kısmen de olsa ÖÇB yaralanması riski azaltılmasına katkı sağlanabilir. Koruyucu egzersiz programlarının daha da geliştirilmesi, yaygınlaşması ve antrenman-rehabilitasyon programlarında yer alması ile birlikte, bu yaralanmanın görülme oranlarında anlamlı azalma hedeflenmektedir. ${ }^{[10]}$

\section{TEMASSIZ YARALANMA RISK FAKTÖRLERi}

\section{Dış (Ekstrinsik, Çevresel) Kaynaklı Risk} Faktörleri

Bu risk faktörlerinin bir kısmı iklim ve hava şartları ile ilgili iken iki tanesi saha zemini ile ilgili, bir tanesi sportif aktivite düzeyi, bir tanesi ise sportif aktiviteye katılan sporcu seviyesi ile ilgilidir. Örneğin yüksek nem altında futbol oynayan bireylerde, spor yaralanması ve dolayısıyla ÖÇB yaralanma riskinin daha yüksek olduğu söylenebilir. ${ }^{[11]}$ Yine düşük yağış alan iklim koşullarındaki zeminlerde nem oranı yüksek olan zeminlere benzer şekilde daha yüksek oranda ÖÇB yaralanması gözlenmektedir. İklim şartlarının ÖÇB yaralanmasına etkisi birçok çalışmada değerlendirilmiş ve yıl içerisinde daha düşük oranda yağış alan bölgelerde ÖÇB yaralanma riski daha yüksek olduğu gözlenmiş, buzlu zemin, artan kar yağışı zemin şartlarını bozarak yine ÖÇB yaralanma riskini yükseltmektedir. ${ }^{[12,13]}$ iklim şartları ve zemin bireysel olarak sporcuların kontrolü dışındadır ancak kısmen de olsa spor organizasyonu yapan kuruluşlar ve yöneticileri tarafından değiştirilebilir ve böylece ÖÇB yaralanma riski daha düşük seviyelere indirilebilir. ${ }^{[13]}$

\section{İç (İntrinsik, Bireysel) Risk Faktörleri}

Bunlar kendi aralarında anatomik, nörovasküler, fizyolojik, biyomekanik ve genetik risk faktörleri olarak başlıklandırılabilir. ${ }^{[14]}$

\section{Anatomik Faktörler}

İnterkondiler çentik mesafesinin medial ve lateral uzunluğunda ve indeksindeki azalma ve darlığı anatomik faktörler arasında en önde gelenlerden birisidir. Bu risk faktörünün varlığı ÖÇB yaralanması için bir predispozan faktördür ve bireylerin anatomik yapısal durumları değiştirilemeyen intrinsik ÖÇB rüptür riski nedenlerindendir. ${ }^{[14,15]}$ Femoral çentiğin, özellikle bayan sporcularda, anterior-posterior düzlemde, her bir milimetre daralması ÖÇB yaralanma riskini artıran faktörlerden birisidir. Bu anatomik risk faktörü değişik popülasyonlarda değerlendirilmiştir. ${ }^{[16,17]}$
Anatomik risk faktörlerinden bir diğeri de tibial slop açısının lateral ve posterior düzlemlerde normalden yüksek olmasıdır. ${ }^{[16]}$ Epifizleri açık olan bireyler pediatrik bireyler olarak kabul edilir ve bu bireylerde açık olan fizisler artmış olan medial slopa neden olur ve bu durum ÖÇB yaralanma riskini artırmaktadır. ${ }^{[18]}$ Bayan sporcularda femoro-tibial plato açısının artması ÖÇB yaralanma riskini artırmaktadır. ${ }^{[19]}$ Artmış alfa açısı, troklear oluk ve tibial tüberositas arasındaki mesafenin artışı, medial ve lateral tibia derinliği ve jeneralize eklem laksitesi ÖÇB yaralanması için diğer predispozan risk faktörleri arasında sayılabilir. Diz eklemindeki rekurvatum deformitesi de ÖÇB rüptürü gelişmesi için predispozan bir faktör olarak sayılabilir. Anatomik nedenlerden bağın kendisi ile ilgili olarak, ön çapraz bağın morfolojik olarak genişliğinin ve volümünün azlığı, ayrıca ligament uzunluğunun artması, ÖÇB rüptürü için predispozan nedenlerden kabul edilmektedir. İnterkondiler çentik mesafesinde yapısal olarak kemik blok varlığı ve neden olduğu sıkışma anatomik nedenlerden sayılabilir. Medial tibial eminens genişliği veya volümünün azalmasının da olası yaralanma riskini artırdığı bilinmektedir. ${ }^{[20]}$

\section{Kuadriseps Kas Gücü}

Eski literatür bilgisi ÖÇB yaralanmalarının primer predispozan nedeni olarak Kuadriseps kas gücünün anterior vektörel kuvveti olarak öne sürülmüştür. ${ }^{[2,20,21]}$ Ancak yapılan birçok MRG (Manyetik Rezonans Görüntüleme) çalışmasında ÖÇB rüptürü olan dizlerde impaksiyon yaralanması olduğu da görülmüştür ve bu durumun, temassız yaralanma sonucu ÖÇB rüptürü olan bireylerde kuadriseps kas kontraksiyonunun tibio-femoral ekleme yüklemiş olduğu kompresif kuvvetlere bağlı olduğu fikrini desteklemektedir. Kuadriseps kas kontraksiyonu ile üretilen anterior çekme kuvvetinden ziyade, tibio-femoral ekleme yüklenen kompresif kuvvetler, ÖÇB rüptüründen sorumlu olmaktadır. ${ }^{[20,22]}$

\section{impingement (Sıkışma)}

ÖÇB'nin femur yapışma bölgesinin karşısında, interkondiler çentiğin medial femoral kondil köşesindeki hipertrofi impingement yani sıkışmaya neden olmaktadır; bu durum ise ÖÇB yaralanmasında predispozan olarak kabul edilip, mekanik nedenler arasında sayılabilir. İnterkondiler çentikdeki stenoz (darlık) midsubstance ÖÇB rüptürünün nedeni olarak gösterilebilir. Genellikle hiperekstansiyondaki diz ekleminde ÖÇB yaralanması meydana gelmesi daha makul görünse de, çoğu ÖÇB yaralanmasının diz eklemi kısmi fleksiyondayken meydana geldiği bilinmektedir. ${ }^{[1,20]}$ 


\section{Aksiyel/Kompresif Güçler}

Aksiyel kompresif yüklerin tibio-femoral ekleme uygulamış olduğu kuvvetlerle ilgili 90'lı yıllarda yapılmış olan birçok çalışmaya kadar geçen dönemde; diz eklemi üzerine ve ÖÇB'ye herhangi bir kuvvet uygulanmadığı düşünülmekteydi ancak aksiyel kompresif güçlerin anterior translasyona ve ÖÇB'de öne doğru yüklenmeye neden olduğu gösterilmiştir. ${ }^{[20,23]}$

Meyer yapmış olduğu kadavra çalışmasında tibiofemoral ekleme aşırı kompresif yüklerin ve internal rotasyonun ÖÇB'de torsiyon ve rüptüre neden olabileceğini göstermiştir. ${ }^{[20]}$ Aksiyel kompresif güçlerin ÖÇB yüklenmesine ve yaralanmasına neden olacağı domuz çalışmalarında da benzer sonuçları vermektedir. ${ }^{[20]}$ Dejour ve Bonnin ${ }^{[24]}$ yapmış oldukları bir çalışmada $10^{\circ}$ üzerinde artmış posterior tibial slobun 6 mm'den fazla tibial anterior translasyona neden olduğunu tanımlamıştır. Posterior tibial slopu artırmak için yapılan osteotomiler anterior tibial translasyonu artırmakta ve dolayısı ile ÖÇB yaralanma riski artmaktadır. ${ }^{[20]}$

\section{Nöromusküler Faktörler}

Genç, aktif erkek veya kadın sporcularda ÖÇB yaralanmasından korunmada kas gücünün etkin rolü bulunmaktadır. ${ }^{[25]}$ İnsan beyninde hareketi kontrol eden merkezlerin hareket esnasındaki instabiliteye reaksiyon verme yeteneği sporcularda ÖÇB rüptür riskini belirlemede önemli rol almaktadır. Nöromusküler faktörlerden olan kalça abduktor ve dış rotatorlarındaki kuvvet yetersizliği vücut ağırlığı ile ilgili olarak ÖÇB rüptür riskini artırmaktadır. ${ }^{26]}$ Hamstring adale grubunun kuadriseps ile birlikte kontraksiyonu ÖÇB rüptürünün oluşmasının önlenmesinde kuadriseps adalesine göre minör, posterior koruyucu olarak görev almaktadır. Özellikle kadın sporcularda hamstring kas güçsüzlüğü sağlıklı genç atletlerle karşılaştırıldığında bir diğer iç kaynakIı risk faktörü olarak tanımlanır. Ayrıca hamstring ve kuadriseps kas güçleri arasındaki imbalans ÖÇB rüptür riskini artırmaktadır. Ayrıca iliotibial bant fleksibilitesinin kaybının da ÖÇB rüptür riski ile ilişkisi vardır. ${ }^{[20]}$

\section{Fizyolojik Faktörler}

Vücut kitle endeksi yüksek olan bireylerde ÖÇB yaralanma riski daha yüksektir. ${ }^{[12]}$ Ayrıca kadınlarda fizyolojik olarak post-menarş ve pre-ovulator fazda ÖÇB rüptür riskinin daha yüksek oranda olduğu görülmektedir. ${ }^{[20,27]}$ Özellikle cinsiyet ve genç yaş risk faktörlerindendir ve bireyler tarafından değiştirilememektedir.

\section{Biyomekanik Faktörler}

Diz ekleminde artmış valgus dizilimi artmış ÖçB riski ile birliktedir ve kalça ekleminde artmış iç ve dış rotasyon ÖÇB rüptürüne zemin hazırlamaktadır. ${ }^{[28]}$

\section{Genetik Faktörler}

COL1A1 gen mutasyonu heriki cinsiyette ÖÇB rüptür riskini artırmaktadır. Metalloproteinaz doku yenilenmesinde kritik bir rol alan enzimdir. ${ }^{[20,29]}$ Proteoglikan gen polimorfizmindeki eksiklik ya da yokluk ÖÇB rüptür riski ile birlikte olabilmektedir ve aile öyküsü ÖÇB yaralanma riski ile birlikte olabilmektedir. ${ }^{[30]}$

\section{SONUÇ}

Bütün dünya çapında her yıl bireysel veya takım sporları ile uğraşan kişilerde ÖÇB yaralanma insidansı arttığı bilinmektedir. ÖÇB yaralanmasında, cerrahi tedavi en sık uygulanan tedavi seçeneğidir. ÖÇB yaralanması sporculara ve sağlık sistemine yüksek maliyet, fiziksel ve psikolojik yük getirdiği bilinmektedir. Bireylere ve toplumun üzerine yüklenmesi bu muhtemel yükün en aza indirilmesi amacıyla ÖÇB yaralanma mekanizmasının anlaşılması, ÖÇB yaralanmasına neden olabilecek predispozan faktörlerin ve bu faktörlere karşı koruyucu tedbirlerin ele alınması her geçen gün daha fazla önem kazanmaktadır.

\section{KAYNAKLAR}

1. Dragoo JL, Castillo TN, Braun HJ, Ridley BA, Kennedy AC, Golish SR. Prospective correlation between serum relaxin concentration and anterior cruciate ligament tears among elite collegiate female athletes. Am J Sports Med 2011;39(10):2175-80. Crossref

2. Boden BP, Dean GS, Feagin JA Jr, Garrett WE Jr. Mechanisms of anterior cruciate ligament injury. Orthopedics 2000;23(6):573-8. Crossref

3. Uhorchak JM, Scoville CR, Williams GN, Arciero RA, St PP, Taylor DC. Risk factors associated with noncontact injury of the anterior cruciate ligament: a prospective four-year evaluation of 859 West Point cadets. Am J Sports Med 2003;31(6):831-42. Crossref

4. DeMorat G, Weinhold P, Blackburn T, Chudik S, Garrett W. Aggressive quadriceps loading can induce noncontact anterior cruciate ligament injury. Am J Sports Med 2004;32(2):47783. Crossref

5. Meyer EG, Baumer TG, Slade JM, Smith WE, Haut RC. Tibiofemoral contact pressures and osteochondral microtrauma during anterior cruciate ligament rupture due to excessive compressive loading and internal torque of the human knee. Am J Sports Med 2008;36(10):1966-77. Crossref

6. Boden BP, Torg JS, Knowles SB, Hewett TE. Video analysis of anterior cruciate ligament injury: abnormalities in hip and ankle kinematics. Am J Sports Med 2009;37(2):252-9. Crossref 
7. Arendt E, Dick R. Knee injury patterns among men and women in collegiate basketball and soccer. NCAA data and review of literature. Am J Sports Med 1995;23(6):694-701. Crossref

8. Uhorchak JM, Scoville CR, Williams GN, Arciero RA, Pierre PS, Taylor DC. Risk factors associated with noncontact injury of the anterior cruciate ligament a prospective fouryear evaluation of 859 west point cadets. Am J Sports Med 2003;31(6):831-42. Crossref

9. Mandelbaum BR, Silvers HJ, Watanabe DS, Knarr JF, Thomas SD, Griffin LY, Kirkendall DT, Garrett W. Effectiveness of a neuromuscular and proprioceptive training program in preventing anterior cruciate ligament injuries in female athletes 2-year follow-up. Am J Sports Med 2005;33(7):100310. Crossref

10. Alentorn-Geli E, Mendiguchía J, Samuelsson K, Musahl V, Karlsson J, Cugat R, Myer GD. Prevention of anterior cruciate ligament injuries in sports -Part I. Systematic review of risk factors in male athletes. Knee Surg Sports Traumatol Arthrosc 2014;22(1):3-15. Crossref

11. Orchard JW, Chivers I, Aldous D, Bennell K, Seward H. Rye grass is associated with fewer non-contact anterior cruciate ligament injuries than bermuda grass. $\mathrm{Br} J$ Sports Med 2005;39(10):704-9. Crossref

12. Ruedl G, Ploner P, Linortner I, Schranz A, Fink C, Patterson C, Nachbauer W, Burtscher M. Interaction of potential intrinsic and extrinsic risk factors in $A C L$ injured recreational female skiers. Int J Sports Med 2011;32(8):618-22. Crossref

13. Pope RP. Rubber matting on an obstacle course causes anterior cruciate ligament ruptures and its removal eliminates them. Mil Med 2002;167(4):355-8. Crossref

14. Souryal TO, Freeman TR. Intercondylar notch size and anterior cruciate ligament injuries in athletes $\mathrm{A}$ prospective study. Am J Sports Med 1993;21(4):535-9. Crossref

15. Everhart JS, Flanigan DC, Simon RA, Chaudhari AM. Association of noncontact anterior cruciate ligament injury with presence and thickness of a bony ridge on the anteromedial aspect of the femoral intercondylar notch. Am J Sports Med 2010;38(8):1667-73. Crossref

16. Simon RA, Everhart JS, Nagaraja HN, Chaudhari AM. A casecontrol study of anterior cruciate ligament volume, tibial plateau slopes and intercondylar notch dimensions in ACLinjured knees. J Biomech 2010;43(9):1702-7. Crossref

17. Shaw KA, Dunoski B, Mardis N, Pacicca D. Knee morphometric risk factors for acute anterior cruciate ligament injury in skeletally immature patients. J Child Orthop 2015;9(2):1618. Crossref

18. Beynnon BD, Hall JS, Sturnick DR, DeSarno MJ, GardnerMorse M, Tourville TW, Smith HC, Slauterbeck JR, Shultz SJ, Johnson RJ, Vacek PM. Increased slope of the lateral tibial plateau subchondral bone associated with greater risk of noncontact ACL injury in females but not in males: a prospective cohort study with a nested, matched case-control analysis. Am J Sports Med 2014;42(5):1039-48. Crossref
19. Vyas S, van Eck CF, Vyas N, Fu FH, Otsuka NY. Increased medial tibial slope in teenage pediatric population with open physes and anterior cruciate ligament injuries. Knee Surg Sports Traumatol Arthrosc 2011;19(3):372-7. Crossref

20. Pfeifer CE, Beattie PF, Sacko RS, Hand A. Risk Factors Associated with Non-contact Anterior Cruciate Ligament Injury: A Systematic Review. Int J Sports Phys Ther 2018;13(4):575-87. Crossref

21. Chappell JD, Creighton RA, Giuliani C, Yu B, Garrett WE. Kinematics and electromyography of landing preparation in vertical stop-jump: risks for noncontact anterior cruciate ligament injury. Am J Sports Med 2007;35(2):235-41. Crossref

22. Viskontas DG, Giuffre BM, Duggal N, Graham D, Parker D, Coolican M. Bone bruises associated with ACL rupture: correlation with injury mechanism. Am J Sports Med 2008;36(5):927-33. Crossref

23. Meyer EG, Haut RC. Excessive compression of the human tibio-femoral joint causes $\mathrm{ACL}$ rupture. J Biomech 2005;38(11):2311-6. Crossref

24. Dejour H, Bonnin M. Tibial translation after anterior cruciate ligament rupture. Two radiological tests compared. J Bone Joint Surg Br 1994;76-B(5):745-9. Crossref

25. Raschner C, Platzer H-P, Patterson C, Werner I, Huber R, Hildebrandt $C$. The relationship between $A C L$ injuries and physical fitness in young competitive ski racers: a 10-year longitudinal study. Br J Sports Med 2011;45(4):310-1. Crossref

26. Khayambashi K, Ghoddosi N, Straub RK, Powers CM. Hip Muscle Strength Predicts Noncontact Anterior Cruciate Ligament Injury in Male and Female Athletes: A Prospective Study. Am J Sports Med 2016;44(2):355-61. Crossref

27. Lefevre N, Bohu Y, Klouche S, Lecocq J, Herman S. Anterior cruciate ligament tear during the menstrual cycle in female recreational skiers. Orthop Traumatol Surg Res 2013;99(5):571-5. Crossref

28. Tainaka K, Takizawa $T$, Kobayashi H, Umimura M. Limited hip rotation and non-contact anterior cruciate ligament injury: a case-control study. Knee 2014;21(1):86-90. Crossref

29. O'Connell K, Knight H, Ficek K, Leonska-Duniec A, Maciejewska-Karlowska A, Sawczuk M, Stepien-Slodkowska M, O'Cuinneagain D, van der Merwe W, Posthumus $M$, Cieszczyk P, Collins M. Interactions between collagen gene variants and risk of anterior cruciate ligament rupture. Eur J Sport Sci 2015;15(4):341-50. Crossref

30. Posthumus M, Collins M, van der Merwe L, O'Cuinneagain D, van der Merwe W, Ribbans WJ, Schwellnus MP, Raleigh SM. Matrix metalloproteinase genes on chromosome 11q22 and the risk of anterior cruciate ligament $(A C L)$ rupture. Scand J Med Sci Sports 2012;22(4):523-33. Crossref 